\title{
Enhanced Intracellular Delivery Using Arginine-Rich Peptides by the Addition of Penetration Accelerating Sequences (Pas)
}

\section{$\operatorname{AUTHOR(S):~}$}

Takayama, Kentaro; Nakase, Ikuhiko; Michiue, Hiroyuki; Takeuchi, Toshihide; Tomizawa, Kazuhito; Matsui, Hideki; Futaki, Shiroh

\section{CITATION:}

Takayama, Kentaro ...[et al]. Enhanced Intracellular Delivery Using Arginine-Rich Peptides by the Addition of Penetration Accelerating Sequences (Pas). Journal of Controlled Release 2009, 138(2): 128-133

\section{ISSUE DATE:}

2009-09-01

URL:

http://hdl.handle.net/2433/134604

\section{RIGHT:}

C 2009 Elsevier Inc.; この論文は出版社版でありません。引用の際には 出版社版をご確認ご利用ください。; This is not the published version. Please cite only the published version. 


\section{Enhanced Intracellular Delivery Using Arginine-Rich Peptides by the Addition of Penetration Accelerating Sequences (Pas)}

Kentaro Takayama ${ }^{\mathrm{a}}$, Ikuhiko Nakase ${ }^{\mathrm{a}}$, Hiroyuki Michiue ${ }^{\mathrm{b}}$, Toshihide Takeuchi ${ }^{\mathrm{a}}$, Kazuhito Tomizawa $^{\mathrm{c}}$, Hideki Matsui*, ${ }^{*}$, Shiroh Futaki*,a

anstitute for Chemical Research, Kyoto University, Uji, Kyoto 611-0011, Japan

${ }^{\mathrm{b}}$ Department of Physiology, Okayama University Graduate School of Medicine, Dentistry and Pharmaceutical Sciences, Okayama 700-8558, Japan

${ }^{\mathrm{c} D e p a r t m e n t ~ o f ~ M o l e c u l a r ~ P h y s i o l o g y, ~ F a c u l t y ~ o f ~ M e d i c a l ~ a n d ~ P h a r m a c e u t i c a l ~ S c i e n c e s, ~}$ Kumamoto University, Honjyo, Kumamoto 860-8556, Japan

* To whom correspondence should be addressed.

Shiroh Futaki, Professor

Institute for Chemical Research, Kyoto University

Uji, Kyoto 611-0011, Japan

Tel: $+81-774-38-3210$

Fax: +81-774-32-3038

E-mail: futaki@scl.kyoto-u.ac.jp

Hideki Matsui, Professor

Department of Physiology, Graduate School of Medicine, Dentistry and Pharmaceutical Sciences, Okayama University

Okayama 700-8558, Japan

Tel: $+81-86-235-7104$

Fax: +81-86-235-7111

E-mail: matsuihi@cc.okayama-u.ac.jp 


\begin{abstract}
Cell penetrating peptides (CPPs), including arginine-rich peptides, are attractive tools for the intracellular delivery of various bioactive molecules with a low membrane permeability. We showed that the accelerated intracellular delivery of arginine-rich peptides was achieved by the addition of a short peptide segment (penetration accelerating sequence, Pas) to arginine-rich CPPs. The cytosolic release of the Pas-attached arginine-rich CPPs was observed within $5 \mathrm{~min}$ after the treatment of the cells with the peptides even in the presence of serum. Effectiveness of the Pas segment in the intracellular delivery of bioactive peptides using arginine-rich CPPs was exemplified through the enhanced growth inhibition activity of the malignant glioma cells by a retro-inverso peptide derived from the p53 C-terminal 22-amino-acid segment (positions 361-382).
\end{abstract}

Keywords: arginine-rich peptide, cell penetrating peptide, intracellular delivery, p53 C-terminal segment, retro-inverso peptide. 


\section{Introduction}

Arginine-rich cell penetrating peptides (CPPs), including the HIV-1 Tat peptide and oligoarginine peptides $(\mathrm{Rn} ; \mathrm{n}=7 \sim 12)$, have been shown to deliver various bioactive molecules with a low membrane permeability into cells to regulate cell functions [1-4, and cited references]. This methodology has attracted our attention not only as a means of cell biological studies, but also because of its potential as therapeutic vectors. Efforts have continued for the development of novel CPPs with a high internalization efficiency, cell specificity, and low cytotoxicity.

One of the important criteria for improving the internalization efficiency of arginine-rich peptides and their conjugates with cargoes should be the efficiency of the endosomal escape $[5,6]$. Involvement of endocytosis, including macropinocytosis, has been pointed out for the cellular uptake of arginine-rich CPPs and their conjugates [7-10 and cited references]. Here the CPP conjugates are delivered into the cells by being trapped in the endosomes, and escape from the endosomal compartments is then necessary for functioning in the cytosol and nucleus. Approaches have been reported for the enhancement of the endosomal escape of the CPP conjugates. Disruption of the endosomes using $\mathrm{pH}$-sensitive fusogenic peptides, such as the influenza hemagglutinin derived peptide HA2 [11] and artificially designed peptide GALA [12], is one approach. The treatment of cells with chloroquine and a photosensitizer may also improve the endosomal escape of the conjugates [13-16]. However, the former approaches employ peptides of more than 20 amino acid residues and the latter approaches may have rooms for further improvement for in vivo applications. Therefore, there remains room for developing more practical approaches.

Cathepsin D is a lysosomal enzyme that can cleave peptide segments such as KPILFFRLK [17]. Considering the contribution of endocytosis to the cellular uptake of arginine-rich CPPs and their conjugates, involvement of this sequence in the CPP conjugates may lead to their partial decomposition in the endosomes/lysosomes that hamper their escape into the cytosol. During the course of our study using the partial segment (GKPILFF) of the above cathepsin D-cleavable sequence, a significant increase in the cellular uptake of octaarginine (R8) was observed by the attachment of this segment (R8-cathD, RRRRRRRR-GKPILFF) (Fig. 1A). Interestingly, the analogue called PasR8 (FFLIPKG-RRRRRRRR) having the retro sequence of R8-cathD was internalized into the cells much more efficiently than R8-cathD. Here, with the hope of enhancing the efficiency of the intracellular delivery by the addition of this FFLIPKG sequence to arginine-rich CPPs, we called the peptide segment FFLIPKG a penetration accelerating sequence (Pas). The hybrid peptide with R8 is thus referred to as PasR8 (Fig. $1 \mathrm{~A})$.

In this study, we report that the attachment of the Pas segment markedly enhanced the endosomal escape of the arginine-rich CPPs, and the growth of the malignant glioma cells was successfully inhibited by conjugation with the p53 C-terminal-derived peptide.

\section{Materials and Methods}

\subsection{Synthesis}

All of the peptides used were chemically synthesized by Fmoc (9-fluorenylmethyloxycarbonyl) solid-phase peptide synthesis on a Rink amide resin as already reported [18]. Deprotection of the peptide and cleavage from the resin were 
conducted by treatment with a trifluoroacetic acid/ethanedithiol mixture (95:5) at room temperature for $3 \mathrm{~h}$ followed by reversed-phase high performance liquid chromatography (HPLC) purification. Fluorescent labeling of the peptides was conducted by treatment with Alexa $488 \mathrm{C}_{5}$ maleimide sodium salt (Invitrogen) in a dimethylformamide (DMF)/methanol mixture (1:1) for $1.5 \mathrm{~h}$ followed by HPLC purification. The structure of the products was confirmed by matrix-assisted laser desorption ionization time-of-flight mass spectrometry (MALDI-TOFMS).

\subsection{Cell culture}

The human cervical cancer-derived HeLa cells were maintained in $\alpha$-minimum essential medium with $10 \%$ heat-inactivated calf serum $[\alpha-\operatorname{MEM}(+)]$. A subculture was performed every 3-4 days. The human malignant glioma cell lines A172 (expressing wild type p53), T98G (expressing the M237I mutant p53 [19]) and U251MG (expressing the R273H mutant p53 (homozygous) [19]) were provided by Health Science Research Resources Bank (Osaka, Japan), and were maintained in Dulbecco's Modified Eagle's Medium [DMEM(+)] with $10 \%$ fetal bovine serum, $100 \mathrm{U} / \mathrm{mL}$ penicillin and $100 \mu \mathrm{g} / \mathrm{mL}$ streptomycin. All cell lines were grown on $100-\mathrm{mm}$ dishes and incubated at $37{ }^{\circ} \mathrm{C}$ under $5 \% \mathrm{CO}_{2}$ to approximately $70 \%$ confluence.

\subsection{Flow cytometry (FACS)}

HeLa cells $\left(7.0 \times 10^{4}\right)$ in fresh culture medium were plated into 24-well microplates (Iwaki) and cultured for $48 \mathrm{~h}$ in $\alpha-\operatorname{MEM}(+)$. After complete adhesion, the cells were incubated at $37{ }^{\circ} \mathrm{C}$ with fresh medium containing fluorescently labeled peptides. After repetitive washing with $\mathrm{PBS}$, the cells were treated with trypsin to ensure the removal of cell-surface-adsorbed peptides [8]. The cells were then washed with PBS and subjected to fluorescence analysis on a FACScalibur (BD Biosciences) flow cytometer using 488-nm laser excitation and a 515- to 545-nm emission filter. For examination of the effect of cytochalasin D (CytD) on the cellular uptake of the peptides, the cells were preincubated with $\mathrm{CytD}(5 \mu \mathrm{M})$ in $\alpha-\operatorname{MEM}(+)$ at $37^{\circ} \mathrm{C}$ for $15 \mathrm{~min}$. The cells were then treated with the peptide in the presence of $5 \mu \mathrm{M}$ CytD and analyzed by FACS. For $4{ }^{\circ} \mathrm{C}$ experiments, cells were preincubated in $\alpha-\operatorname{MEM}(+)$ at $4{ }^{\circ} \mathrm{C}$ for $1 \mathrm{~h}$. The cells were washed, incubated in $\alpha-\operatorname{MEM}(+)$ containing peptides at $4{ }^{\circ} \mathrm{C}$ and analyzed by FACS.

\subsection{Confocal microscopy}

HeLa cells $\left(2 \times 10^{5}\right)$ were plated on $35-\mathrm{mm}$ glass-bottomed dishes (Iwaki) and cultured in $\alpha-\operatorname{MEM}(+)$ for $48 \mathrm{~h}$. After complete adhesion, the culture medium was exchanged, and the cells were then incubated at $37{ }^{\circ} \mathrm{C}$ with fresh medium containing the fluorescently labeled peptides. After the incubation period, the cells were washed with PBS, and fresh culture medium was added. Distribution of the fluorescently labeled peptides was then analyzed using a confocal laser scanning microscope (CLSM) FV300 (Olympus) equipped with a $40 \times$ objective without fixing the cells to avoid artifactual localization of the internalized peptides $[8,20]$. For examination of the effects of CytD on the cellular uptake of the peptides, the cells were preincubated with $\mathrm{CytD}(5 \mu \mathrm{M})$ in $\alpha-\operatorname{MEM}(+)$ at $37{ }^{\circ} \mathrm{C}$ for $15 \mathrm{~min}$. The cells were then treated with the peptide in $\alpha-\operatorname{MEM}(+)$ in the presence of $5 \mu \mathrm{M}$ CytD and analyzed by CLSM. For the $4{ }^{\circ} \mathrm{C}$ experiments, the cells were preincubated at $4{ }^{\circ} \mathrm{C}$ for $1 \mathrm{~h}$. After the pretreatment period, 
the cells were washed, incubated in $\alpha-\operatorname{MEM}(+)$ containing peptides at $4{ }^{\circ} \mathrm{C}$ and analyzed by CLSM.

\subsection{Cell viability assay}

A172, T98G and U251MG glioma cells $\left(1.0 \times 10^{3}\right)$ were suspended in fresh $\operatorname{DMEM}(+)$ containing peptides $(100 \mu \mathrm{L})$ and each plated into 96-well microplates (Iwaki). Cell viability at each time point $(4,24,48,72$ and $96 \mathrm{~h})$ was determined using the WST-1 (4-[3-(4-iodophenyl)-2-(4-nitrophenyl)-2H-5-tetrazolio]-1,3-benzene disulfonate) assay, according to the manufacturer's protocol (Roche Applied Science) as already reported [11]. The MTT [3-(4,5-dimethylthiazol-2-yl)-2,5-diphenyl-2Htetrazolium bromide] assay was conducted as already reported [21].

\section{Results}

3.1 Rapid cellular uptake and cytosolic distribution of octaarginine peptides bearing the penetration accelerating sequence (Pas) segment

The R8-cathD peptide has a hybrid sequence of the octaarginine (R8) CPP with the GKPILFF segment derived from a cathepsin D-cleavable sequence [17]. The PasR8 peptide has the retro sequence of R8-cathD (Fig. 1A). The result of the analysis of the internalization efficiency of these peptides analyzed by FACS is given in Fig. 1B in which the HeLa cells were treated with these peptide $\left(10 \mu \mathrm{M}\right.$ each) for $30 \mathrm{~min}$ at $37^{\circ} \mathrm{C}$ in $\alpha-\operatorname{MEM}(+)$ prior to the FACS analysis.

A)

$$
\begin{aligned}
& \frac{\text { PasR8 }}{\text { FFLIPKGGRRRRRRRR-GC(Alexa)-amide }} \\
& \frac{\text { R8-cathD }}{\text { RRRRRRRRGKPILFF-GC(Alexa)-amide }}
\end{aligned}
$$

$\underline{\mathrm{R} 8}$

RRRRRRRR-GC(Alexa)-amide

B)

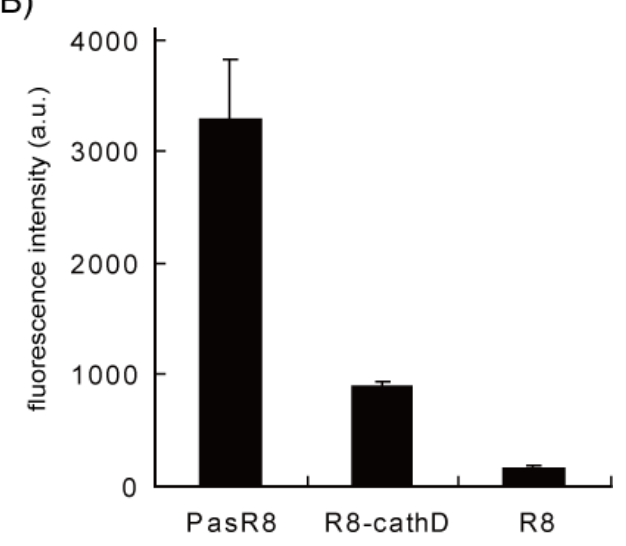

Fig. 1

A) Structures of fluorescently labeled peptides used in this study in which an extension sequence of the Gly-Cys-amide was employed for the Alexa labeling. The dashed underline represents the Pas segment. B) Cellular uptake of PasR8 analyzed by FACS. Cell line, HeLa; peptides, $10 \mu \mathrm{M}$; incubation, for $30 \mathrm{~min}$ at $37^{\circ} \mathrm{C}$ in $\alpha-\operatorname{MEM}(+)$. Means \pm standard deviation (s.d.) of three experiments are shown.

The amount of cellular uptake of R8-cathD was 5 times that of R8 (Fig. 1B). More surprisingly, that of PasR8 was about 18 times that of R8. Therefore, attachment of the Pas sequence (FFLIPKG) to R8 significantly enhanced the internalization. In addition, 
the cellular uptake of PasR4 (FFLIPKG-RRRR) that lacks four arginine residues from PasR 8 was slightly less than that of R8 (data not shown). This suggests that there may be a synergetic effect by using both the Pas and R8 segment for the uptake enhancement.

A time course study of the cellular uptake of PasR8 showed a steep increase in the first 30 min to attain a plateau within 60 min under the given conditions (Fig. 2A). On the other hand, the amount of cellular uptake of R8 kept increasing during the observation period without reaching a plateau. The amount of PasR 8 taken up by the cells in 30 min was more than 10 times that of R8. This result suggested the significant contribution of the Pas segment to accelerate the cellular uptake of R8. As shown in Fig. 2B, diffuse signals of PasR8 into the cytosol and nucleus were observed by a confocal microscopic analysis in the first 5 min after the peptide treatment of the cells, whereas very few fluorescence signals were observed for R8 (Fig. 2B). A prolonged incubation for 180 min with PasR8 yielded the peptide signals colocalizing with the lysosome marker, Lysotracker. However, diffuse signals of PasR 8 were predominantly observed in cytosol and nucleus (Supplementary data Fig. S1). In contrast, the R8 peptide only gave endosome-like punctate signals (Fig. S1), suggesting the facilitated endosomal escape by the addition of the Pas segment, and this would be favorable for delivering cargoes to influence the cellular activity and functions. In addition, there was no significant cytotoxicity of PasR8 under the given conditions analyzed by the MTT assay and the

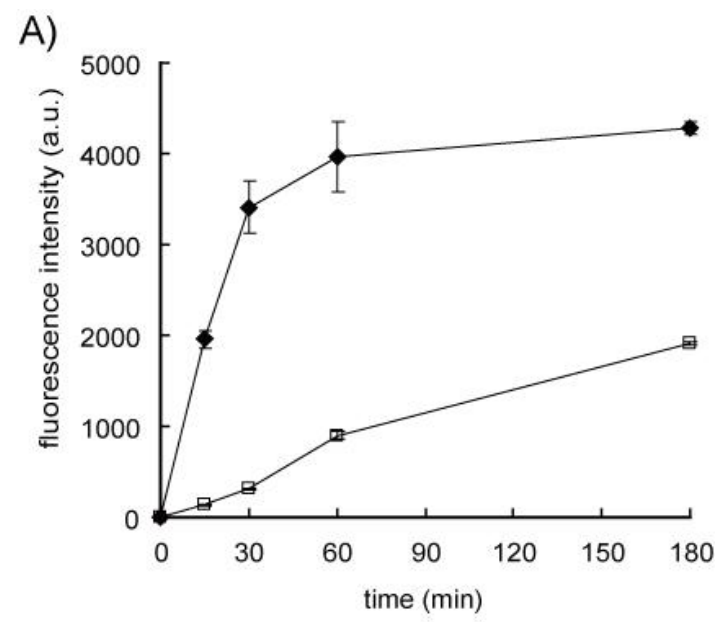

B)

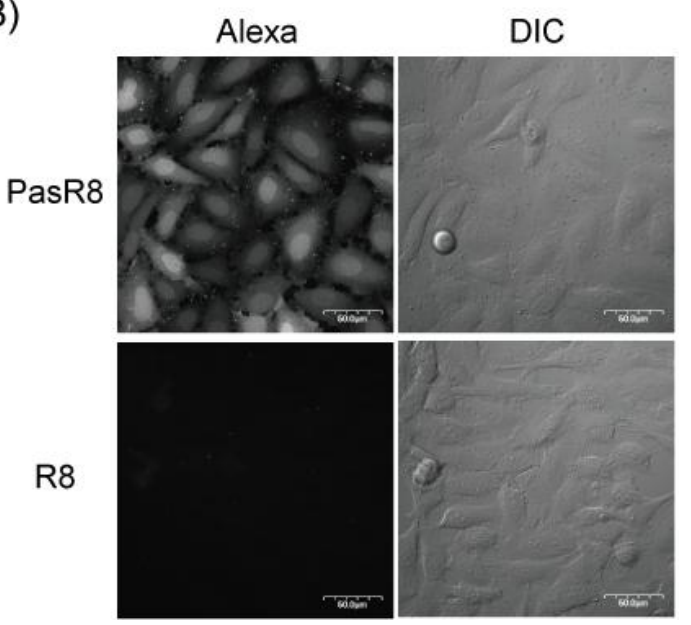

Fig. 2

A) Time course of cellular uptake of PasR8 (closed diamond) and R8 (open square). Cell line, HeLa; peptides, 10 $\mu \mathrm{M}$; incubation, $15,30,60$, and 180 $\min$ at $37{ }^{\circ} \mathrm{C}$ in $\alpha-\operatorname{MEM}(+)$. The experiments were performed in triplicate. Error bars show the s.d. B) Rapid intracellular diffusion of PasR8. Cell line, HeLa; peptides, $10 \mu \mathrm{M}$; incubation, $5 \mathrm{~min}$ at $37{ }^{\circ} \mathrm{C}$ in $\alpha-\operatorname{MEM}(+)$. Cells were washed three times with PBS after incubation and then observed by CLSM without fixation. Scale bars, $50 \mu \mathrm{m}$. 
lack of nuclear staining with a membrane impermeable dye, propidium iodide also assured the integrity of the plasma membranes [22] (data not shown). Importantly, this diffusion of PasR8 is observed in serum-containing medium, typically at the peptide concentration $>5 \mu \mathrm{M}$ (Supplementary data Fig. S2). We previously reported that the serum-binding of the oligoarginine peptides results in a considerable decrease in the effective concentration of the peptides in the cultured media and this may hamper the cytosolic diffusion of the peptides [22]. The addition of the Pas sequence to R8 should be promising for obtaining a higher biological activity in cells.

\subsection{Energy-dependent intracellular diffusion of PasR8}

The contribution of endocytosis including macropinocytosis has been pointed out for the internalization of oligoarginine peptide. On the other hand, the possibility of the energy-independent direct penetration of oligoarginine to yield a diffuse cytosolic distribution of the peptides has been suggested when the concentration of the peptides exceeds a certain threshold [22]. Because PasR8 yielded significantly diffuse signals in the cytosol and nucleus within $5 \mathrm{~min}$ after the peptide treatment, the internalization methods of PasR8 were studied with R8 as a reference. HeLa cells were treated with 10 $\mu \mathrm{M}$ PasR 8 and $\mathrm{R} 8$ at 37 and $4{ }^{\circ} \mathrm{C}$ in $\alpha$-MEM(+) for $15 \mathrm{~min}$ and analyzed by FACS (Fig. $3 \mathrm{~A})$. There was an $\sim 14$-fold decrease in the amount of cellular uptake of PasR 8 at $4{ }^{\circ} \mathrm{C}$ compared to that at $37{ }^{\circ} \mathrm{C}$. Note that the amount of cellular uptake of PasR 8 even at $4{ }^{\circ} \mathrm{C}$ was still comparable to that at $37{ }^{\circ} \mathrm{C}$ of $\mathrm{R} 8$ (Fig. 3A). The treatment of cells with cytochalasin $\mathrm{D}(\mathrm{CytD})$ prevents actin polymerization and the eventual macropinocytic uptake of R8 [8]. Similarly in the case of R8, the cellular uptake of PasR8 was inhibited to $60 \%$ by treatment with CytD (Fig. 3B). These results suggested that the cellular uptake of PasR8 employs energy-dependent pathways and macropinocytosis can be involved in the cellular uptake in which actin polymerization plays an important role.

A)

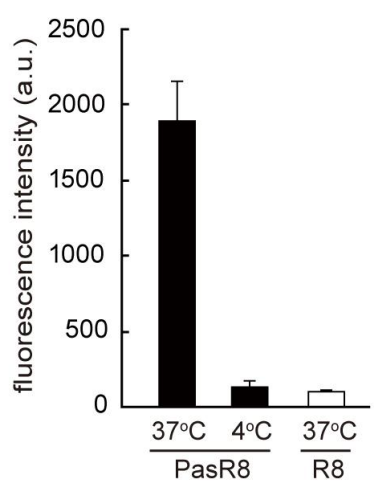

C)

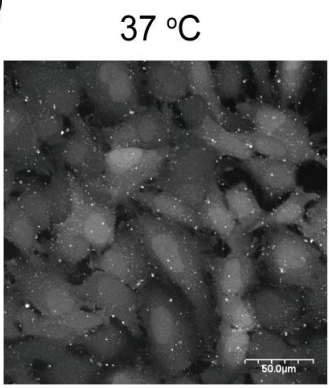

B)

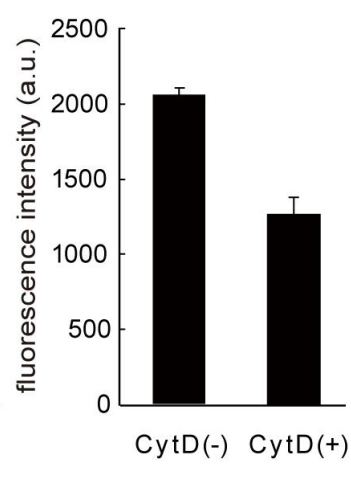

$4^{\circ} \mathrm{C}$

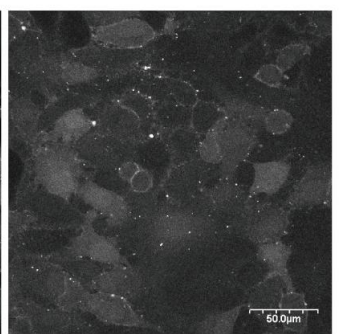

Fig. 3

A) FACS analysis of the cellular uptake of PasR8 (black) and R8 (white) under a low temperature treatment. Cell line, HeLa; peptide, $10 \mu \mathrm{M}$; incubation, 15 min at $37{ }^{\circ} \mathrm{C}$ or $4{ }^{\circ} \mathrm{C}$ in $\alpha-\operatorname{MEM}(+)$. Means \pm s.d. of three experiments are shown. B) Cellular uptake of PasR8 in the presence or absence of cytochalasin D (CytD) $(5 \mu \mathrm{M})$. Cell line, HeLa; peptide, $10 \mu \mathrm{M}$; incubation, $15 \mathrm{~min}$ at $37^{\circ} \mathrm{C}$ in $\alpha-\operatorname{MEM}(+)$. Means \pm s.d. of three experiments are shown. C) CLSM images of PasR8 $(10 \mu \mathrm{M})$ incubated with HeLa cells at $37{ }^{\circ} \mathrm{C}$ and $4{ }^{\circ} \mathrm{C}$ for $15 \mathrm{~min}$ in $\alpha-\operatorname{MEM}(+)$. Scale bars, $50 \mu \mathrm{m}$. 
The CLSM analysis of cells treated with PasR 8 at $4^{\circ} \mathrm{C}$ resulted in signals to a lesser extent than at $37^{\circ} \mathrm{C}$ (Fig. 3C), suggesting that the cytosolic diffusion of PasR 8 at $37^{\circ} \mathrm{C}$ is predominantly achieved during the early stage of the endocytic pathway, followed by leakage of the peptide through the endosomal membranes. On the other hand, diffuse signals of PasR 8 were still observed in the cytosol and nucleus at $4{ }^{\circ} \mathrm{C}$. This suggested the possible involvement of the energy-independent direct penetration pathways of PasR8 through the plasma membranes under the given conditions. Similar methods of cytosolic diffusion are also observed for cells treated with $\mathrm{R} 8$ at $4{ }^{\circ} \mathrm{C}[8,23]$.

\subsection{Efficient internalization of flock house virus (FHV)-derived arginine-rich peptides bearing Pas}

To examine whether the addition of the Pas sequence to other arginine-rich peptides may also lead to the promotion of their cellular uptake, the flock house virus (FHV) coat protein-derived peptide [21] was employed as an example (Fig. 4A). The FHV peptide shows a higher internalization efficiency compared to the typical arginine-rich CPPs such as R8 and HIV-1 Tat peptides (the details will be reported elsewhere). We similarly attached the Pas segment to this peptide (PasFHV) (Fig. 4A) and evaluated the internalization efficiency into the cell. Almost an 8-fold increase in the cellular uptake was attained by the addition of the Pas segment to the FHV peptide (Fig. 4B). The CLSM analysis also showed an efficient distribution of PasFHV in the cytosolic and nucleic compartments (data not shown). A significant increase in the cellar uptake by the addition of the Pas segment was also observed for the Tat peptide (Supplementary data Fig. S3). These results suggested the generality of facilitating the cellular uptake of the arginine-rich CPPs by the addition of the Pas segment.

A)

\section{PasFHV}

\section{FFLIPKGRRRRNRTRRNRRRVR-GC(Alexa)-amide}

\section{$\underline{\mathrm{FHV}}$}

RRRRNRTRRNRRRVR-GC(Alexa)-amide

B)

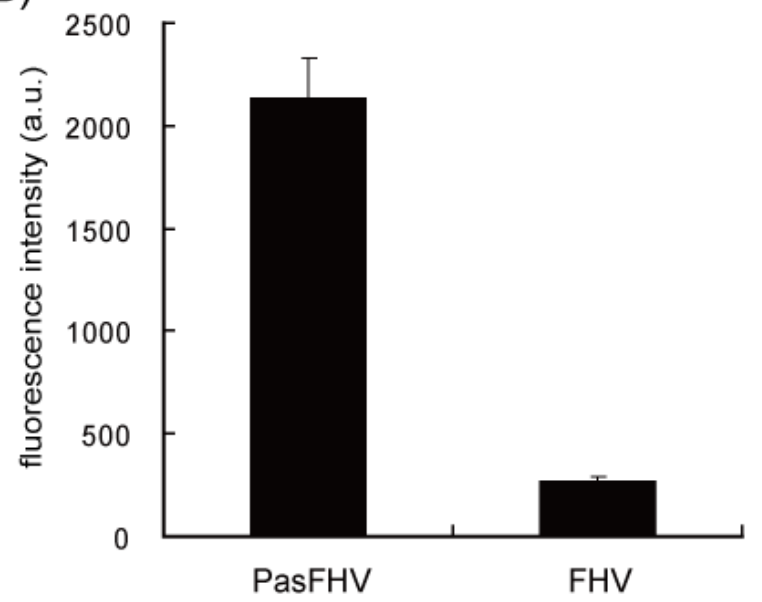

Fig. 4

A) Structures of fluorescently-labeled PasFHV and FHV peptides bearing a Gly-Cys-amide segment for Alexa labeling. The Pas segment is highlighted by the dashed line. B) Enhanced cellular uptake by the attachment of the Pas segment to the FHV peptide. The HeLa cells were treated with a $10 \mu \mathrm{M}$ peptide for $15 \mathrm{~min}$ at $37^{\circ} \mathrm{C}$ in $\alpha$-MEM(+); Means \pm s.d. of three experiments are shown. 
3.4 Enhanced growth inhibition of malignant cells by intracellular delivery of a p53 C-terminal-derived peptide using the FHV peptide with the Pas segment

The effectiveness of the Pas addition to the intracellular delivery using arginine-rich peptides was evaluated through the delivery of a p53 C-terminal-derived peptide. A peptide segment derived from the p53 C-terminal 22 amino acid (361-382) has been reported to induce p53-dependent cell death in malignant cell lines [24,25]. The retro-inverso peptides that are composed of D-amino acids and have the sequences in the reverse order of the original peptides have side-chain spatial arrangements similar to those of the original peptides [26]. Because the D-amino acid segments are less susceptible to proteolytic degradation, the retro-inverso peptides are assumed to show a prolonged biological effect analogous to that of the original peptides. It has been reported that the retro-inverso version of the above p53-derived peptide (p53C') was successfully delivered into cells by conjugation with the Tat peptide and showed a sustained inhibition of cancer growth [27]. Using the flock house virus (FHV)-derived arginine-rich peptide, the effect of the Pas addition to this CPP was evaluated through the growth inhibition of malignant cells attained by the intracellularly delivered $\mathrm{p} 53 \mathrm{C}^{\prime}$ peptide using the WST-1 assay.

Three kinds of human malignant glioma cells expressing the wild type p53 protein (A172) and mutant p53 proteins (T98G and U251MG) were employed, and the growth inhibition of these cells by the treatment with peptides was examined for $96 \mathrm{~h}$. The latter cell lines expressing the mutant p53 proteins have a diminished p53 activity, which often provides these cells with a resistance to anti-cancer reagents. Considering the prolonged incubation periods, the D-amino acid versions of the FHV (dFHV) and PasFHV (dPasFHV) peptides were employed as the delivery vectors, and their hybrid peptides

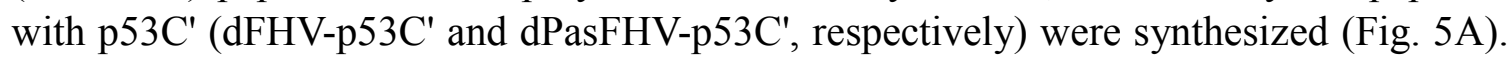
The effect of dPasFHV-p53C' on the cell growth of A172 cells was first evaluated using various concentrations $(1-10 \mu \mathrm{M})$ of the peptides at 4, 24, 48, 72 and $96 \mathrm{~h}$ (day 0-4), using the WST-1 assay. Significant suppression of the cell growth was observed at the peptide concentration of $5 \mu \mathrm{M}$. Incubation of the cells with $10 \mu \mathrm{M}$ dPasFHV-p53C' resulted in complete suppression of the proliferation (Fig. 5B). Note that a single dose of peptides was applied to the cells only at time zero. The $10 \mu \mathrm{M}$ dPasFHV-p53C' yielded no significant proliferation not only of the wild-type, but also the mutant p53 expressing cells within $96 \mathrm{~h}$ (Fig. 5C). In contrast, only a slight suppression of proliferation was observed for the dFHV-p53C'-treated cells compared with the non-treated control cells. We also evaluated the conjugate of dPasFHV and mutant $\mathrm{p}^{2} 3 \mathrm{C}^{\prime}$ (dPasFHV-mp53 $\mathrm{C}^{\prime}$ );

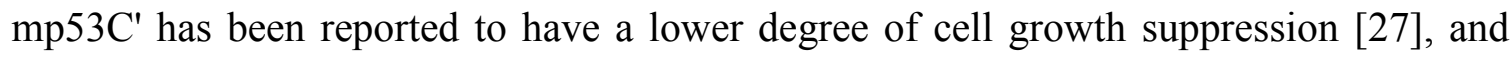

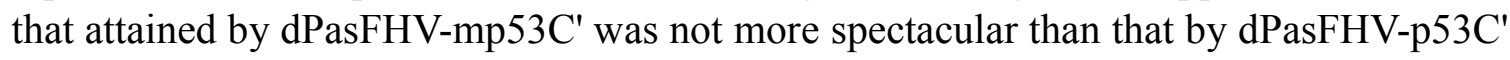
(Fig. 5C). In addition, $10 \mu \mathrm{M}$ dPas-p53C' lacking the FHV segment (FFLIPKG-KKHRSTSQGKKSKLHSSHARSG-amide) yielded no significant cell growth inhibition (data not shown). Substitution of the dPasFHV segment to its L-isomer peptide also resulted in the almost complete loss of the suppression effect (Supplementary data Fig. S4). Employment of dPasR8 (D-amino acid versions of PasR8) instead of dPasFHV also yielded a reduced suppression effect (Supplementary data Fig. S4). Therefore, by conjugating the $\mathrm{p} 53 \mathrm{C}^{\prime}$ peptide with $\mathrm{dPasFHV}$, a long-lasting suppression of malignant cell growth was attained. 
A) dPasFHV-p53C'

FFLIPKGRRRRNRTRRNRRRVR-GKKHRSTSQGKKSKLHSSHARSG-amide dFHV-p53C'

RRRRNRTRRNRRRVR-G-

KKHRSTSQGKKSKLHSSHARSG-amide

dPasFHV-mp53C

FFLIPKGRRRRNRTRRNRRRVR-G-

KKHRSTSQGEASELHSSHARSG-amide

B)

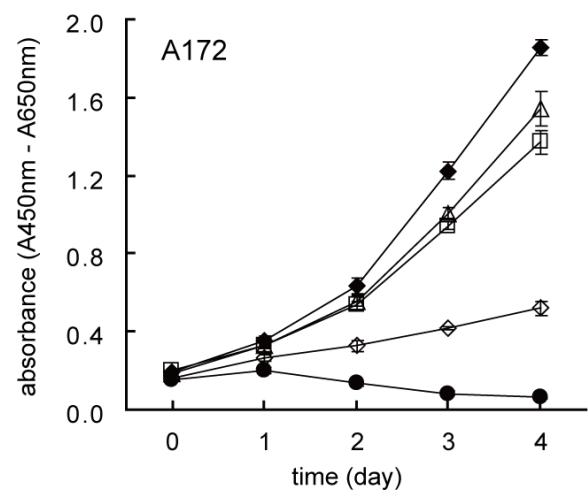

C)
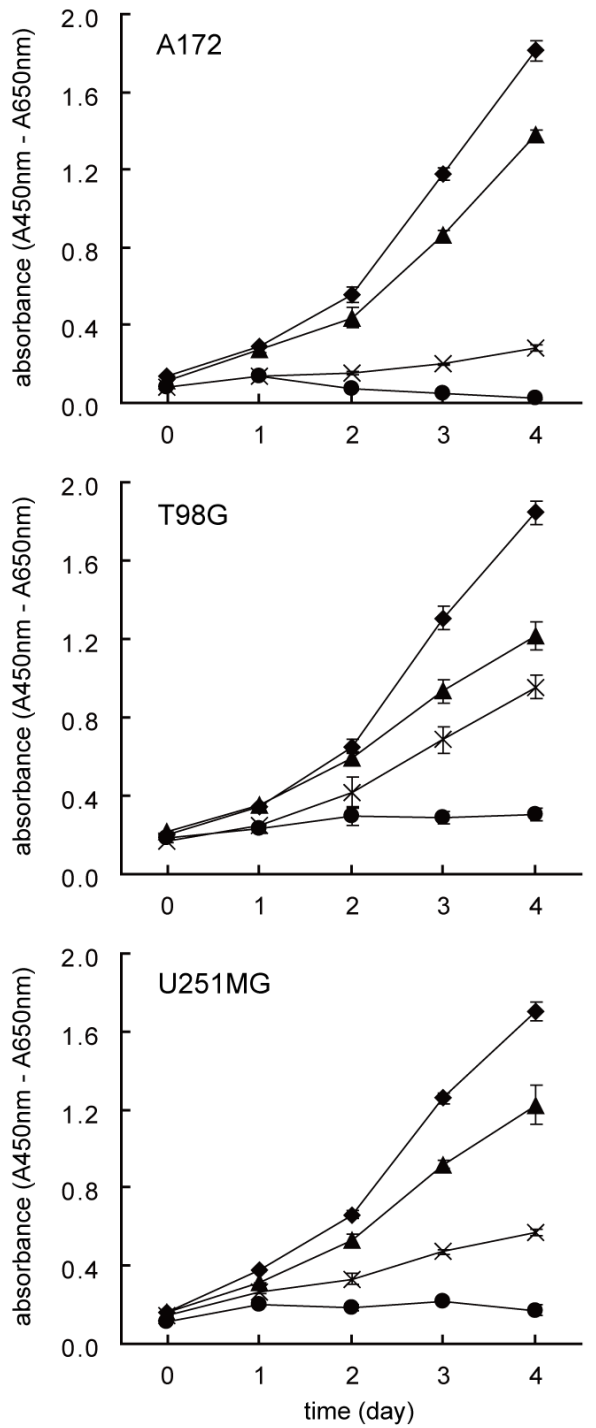

Fig. 5

A) Structures of dPasFHV-p53C' and dFHV-p53C'. The Pas segment is highlighted by the dashed line. The D-amino acids are shown in italics. A Gly residue was inserted as a linker to connect between the dPasFHV/dFHV and the p53C' segments. B) Concentration dependence of dPasFHV-p53C' during the effect of the peptide treatment on proliferation of the human malignant glioma A172 cells. peptide, 1, 2, 5 and 10 $\mu \mathrm{M}$; incubation, 4, 24, 48, 72 and $96 \mathrm{~h}$ (day 0-4) at $37^{\circ} \mathrm{C}$ in $\operatorname{DMEM}(+)$. Means \pm s.d. of three experiments are shown. C) Effect of the peptide treatment on proliferation of the human malignant glioma cells. Circle, dPasFHV-p53C'; triangle, $\mathrm{dFHV}-\mathrm{p} 53 \mathrm{C}^{\prime} ; \quad$ cross, dPasFHV-mp53C' [mutant p53 C' peptides (mp53 $\left.\mathrm{C}^{\prime}\right)$ were designed by the substitution of three Lys with Glu or Ala, according to ref. 27)]; diamond, control. Cell line, A172 (upper panel), T98G (middle panel) and U251MG (lower panel); peptide, $10 \mu \mathrm{M}$; incubation, 4, 24, 48, 72 and $96 \mathrm{~h}$ (day $0-4$ ) at $37{ }^{\circ} \mathrm{C}$ in $\operatorname{DMEM}(+)$. Means \pm s.d. of three experiments are shown. 


\section{Discussion}

There is a growing interest in the utilization of CPPs as a vector for the intracellular delivery of bioactive molecules of low membrane permeability, and efforts are continuing to develop novel vectors of a high translocation efficiency. Endosomal escape of the CPPs into the cytosol is among the focuses of this challenge. A considerable portion of the CPPs is taken up by the cells using endocytosis including macropinocytosis and, in most cases, intracellularly delivered cargoes have to be delivered into the cytosol to exert their biological activity. In this study, we showed that the addition of a small peptide segment called a penetration accelerating sequence (Pas) significantly enhances the internalization efficiency of arginine-rich CPPs including the R8 and FHV peptides. Effective cytosolic diffusion of the PasR 8 and PasFHV peptides was observed even in the presence of serum by CLSM observation. In addition, a significant decrease in the cellular uptake of PasR8 was observed at low temperature or during CytD treatment. These results suggest that PasR8 was predominantly taken up by the cells via endocytosis, followed by its efficient leakage from the endosomes into the cytosol. Considering that R8 without the Pas segment often yields punctate signals under the same conditions, a considerable amount of R8 is trapped in the endosomes. Therefore, the additional Pas segment may accelerate the translocation of PasCPPs through the endosomal membranes. In addition, a significant cytosolic diffusion of PasCPPs observed after only $5 \mathrm{~min}$ of peptide treatment of the cells strongly suggested that efficient leakage of the peptides from the endosomes was accomplished in the very early stages of their endocytic uptake. The detailed mechanism of this Pas-stimulated endosomal escape is currently under study in our laboratory. One possible explanation should be that the somewhat hydrophobic nature of the Pas segment (FFLIPKG) would increase the interaction of the peptides with the membranes to accelerate the release of the endosome-trapped peptides into the cytosol. However, considering that PasR8 and R8-cathD should have similar degree of hydrophobicity, there may be some factors other than hydrophobicity to explain the superiority of PasR8 in the cellular uptake.

The addition of the Pas segments led to effective cytosolic diffusion of the fluorescently labeled R8 and FHV peptides even in a serum-containing medium. Assuming that the fluorescent moiety is a model of small molecular weight compounds, an increase in the cytosolic activity of the delivered cargo is also expected. This was exemplified through the growth inhibition of human malignant glioma cells by the delivery of the proteolytic resistant retro-inverso segment of a p53 C-terminal segment $\left(\mathrm{p} 53 \mathrm{C}^{\prime}\right)$. Almost complete inhibition of the cell growth was observed by the single administration of dPasFHV-p53C' $(10 \mu \mathrm{M})$, whereas only a slight inhibition was achieved in the dFHV-p53C'-treated cells. Of course, there may be a certain cargo effect in the cellular localization and internalization efficiency even in the delivery using PasCPPs, as pointed out for the CPP-mediated delivery [28]. However, this approach of the Pas attachment may provide a new platform for the intracellular delivery using CPPs.

\section{Acknowledgement}

This work was supported in part by Grants-in-Aid for Scientific Research from the Ministry of Education, Culture, Sports, Science and Technology of Japan and from the Ministry of Health, Labour and Welfare of Japan. K. T. is grateful for a JSPS Research Fellowship for Young Scientists. 


\section{References}

[1] S. Futaki (Ed.), Special theme issue on membrane permeable peptide vectors: chemistry and functional design for the therapeutic applications, Adv. Drug Delivery Rev. 60 (2008) 447-614.

[2] A. Joliot, A. Prochiantz, Transduction peptides: from technology to physiology, Nat. Cell Biol. 6 (2004) 189-196.

[3] U. Langel (Ed.), Handbook of cell-penetrating peptides, 2nd ed., CRC press, London, 2006.

[4] K. Kogure, H. Akita, H. Harashima, Multifunctional envelope-type nano device for non-viral gene delivery: Concept and application of Programmed Packaging, J. Controlled Release 122 (2007) 246-251.

[5] S. Abes, D. Williams, P. Prevot, A. Thierry, M.J. Gait, B. Lebleu, Endosome trapping limits the efficiency of splicing correction by PNA-oligolysine conjugates, J. Controlled Release 110 (2006) 595-604.

[6] J.C. Cheung, P.K. Chiaw, C.M. Deber, C.E. Bear, A novel method for monitoring the cytosolic delivery of peptide cargo, J. Controlled Release, in press.

[7] R. Abes, A.A. Arzumanov, H.M. Moulton, S. Abes, G.D. Ivanova, P.L. Iversen, M.J. Gait, B. Lebleu, Cell-penetrating-peptide-based delivery of oligonucleotides: an overview, Biochem. Soc. Trans. 35 (2007) 775-779.

[8] I. Nakase, M. Niwa, T. Takeuchi, K. Sonomura, N. Kawabata, Y. Koike, M. Takehashi, S. Tanaka, K. Ueda, J.C. Simpson, A.T. Jones, Y. Sugiura, S. Futaki, Cellular uptake of arginine-rich peptides: roles for macropinocytosis and actin rearrangement, Mol. Ther. 10 (2004) 1011-1022.

[9] A.T. Jones, Macropinocytosis: searching for an endocytic identity and role in the uptake of cell penetrating peptides, J. Cell. Mol. Med. 11 (2007) 670-684.

[10] I.M. Kaplan, J.S. Wadia, S.F. Dowdy, Cationic TAT peptide transduction domain enters cells by macropinocytosis, J. Controlled Release 102 (2005) 247-253.

[11] H. Michiue, K. Tomizawa, F.Y. Wei, M. Matsushita, Y.F. Lu, T. Ichikawa, T. Tamiya, I. Date, H. Matsui, The NH2 terminus of influenza virus hemagglutinin-2 subunit peptides enhances the antitumor potency of polyarginine-mediated p53 protein transduction, J. Biol. Chem. 280 (2005) 8285-8289.

[12] S. Kobayashi, I. Nakase, N. Kawabata, H.H. Yu, S. Pujals, M. Imanishi, E. Giralt, S. Futaki, Cytosolic targeting of macromolecules using a $\mathrm{pH}$-dependent fusogenic peptide in combination with cationic liposomes, Bioconjugate Chem. in press.

[13] N.J. Caron, S.P. Quenneville, J.P. Tremblay, Endosome disruption enhances the functional nuclear delivery of Tat-fusion proteins, Biochem. Biophys. Res. Commun. 319 (2004) 12-20.

[14] S. Yang, D.J. Coles, A. Esposito, D.J. Mitchell, I. Toth, R.F. Minchin, Cellular uptake of self-assembled cationic peptide-DNA complexes: multifunctional role of the enhancer chloroquine, J. Controlled Release 135 (2009) 159-165.

[15] A. Høgset, L. Prasmickaite, P.K. Selbo, M. Hellum, B.Ø. Engesaeter, A. Bonsted, K. Berg, Photochemical internalisation in drug and gene delivery, Adv. Drug Delivery Rev. 56 (2004) 95-115.

[16] M. Matsushita, H. Noguchi, Y.F. Lu, K. Tomizawa, H. Michiue, S.T. Li, K. Hirose, S. Bonner-Weir, H. Matsui, Photo-acceleration of protein release from endosome in 
the protein transduction system, FEBS Lett. 572 (2004) 221-226.

[17] Y. Yasuda, T. Kageyama, A. Akamine, M. Shibata, E. Kominami, Y. Uchiyama, K. Yamamoto, Characterization of new fluorogenic substrates for the rapid and sensitive assay of cathepsin E and cathepsin D, J. Biochem. 125 (1999) 1137-1143.

[18] S. Futaki, M. Niwa, I. Nakase, A. Tadokoro, Y. Zhang, M. Nagaoka, N. Wakako, Y. Sugiura, Arginine carrier peptide bearing Ni(II) chelator to promote cellular uptake of histidine-tagged proteins, Bioconjugate Chem. 15 (2004) 475-481.

[19] J. Wischhusen, U. Naumann, H. Ohgaki, F. Rastinejad, M. Weller, CP-31398, a novel p53-stabilizing agent, induces p53-dependent and p53-independent glioma cell death, Oncogene 22 (2003) 8233-8245.

[20] J.P. Richard, K. Melikov, E. Vivès, C. Ramos, B. Verbeure, M.J. Gait, L.V. Chernomordik, B. Lebleu, Cell penetrating peptides. A reevaluation of the mechanism of cellular uptake, J. Biol. Chem. 278 (2003) 585-590.

[21] S. Futaki, T. Suzuki, W. Ohashi, T. Yagami, S. Tanaka, K. Ueda, Y. Sugiura, Arginine-rich peptides. An abundant source of membrane-permeable peptides having potential as carriers for intracellular protein delivery, J. Biol. Chem. 276 (2001) 5836-5840.

[22] M. Kosuge, T. Takeuchi, I. Nakase, A.T. Jones, S. Futaki, Cellular internalization and distribution of arginine-rich peptides as a function of extracellular peptide concentration, serum, and plasma membrane associated proteoglycans, Bioconjugate Chem. 19 (2008) 656-664.

[23] M.M. Fretz, N.A. Penning, S. Al-Taei, S. Futaki, T. Takeuchi, I. Nakase, G. Storm, A.T. Jones, Temperature-, concentration- and cholesterol-dependent translocation of L- and D-octa-arginine across the plasma and nuclear membrane of CD34+ leukaemia cells, Biochem. J. 403 (2007) 335-342.

[24] G. Selivanova, V. Iotsova, I. Okan, M. Fritsche, M. Ström, B. Groner, R.C. Grafström, K.G. Wiman, Restoration of the growth suppression function of mutant p53 by a synthetic peptide derived from the p53 C-terminal domain, Nat. Med. 3 (1997) 632-638.

[25] Y. Li, R.V. Rosal, P.W. Brandt-Rauf, R.L. Fine, Correlation between hydrophobic properties and efficiency of carrier-mediated membrane transduction and apoptosis of a p53 C-terminal peptide, Biochem. Biophys. Res. Commun. 298 (2002) 439-449.

[26] M. Chorev, M. Goodman, A dozen years of retro-inverso peptidomimetics, Acc. Chem. Res. 26 (1993) 266-273.

[27] E.L. Snyder, B.R. Meade, C.C. Saenz, S.F. Dowdy, Treatment of terminal peritoneal carcinomatosis by a transducible p53-activating peptide, PLoS Biol. 2 (2004) 186-193.

[28] G. Tünnemann, R.M. Martin, S. Haupt, C. Patsch, F. Edenhofer, M.C. Cardoso, Cargo-dependent mode of uptake and bioavailability of TAT-containing proteins and peptides in living cells, FASEB J. 20 (2006) 1775-1784. 
Supplementary data:

\section{Enhanced Intracellular Delivery Using Arginine-Rich Peptides by the Addition of Penetration Accelerating Sequences (Pas)}

Kentaro Takayama ${ }^{\mathrm{a}}$, Ikuhiko Nakase ${ }^{\mathrm{a}}$, Hiroyuki Michiue ${ }^{\mathrm{b}}$, Toshihide Takeuchi ${ }^{\mathrm{a}}$, Kazuhito Tomizawa $^{\mathrm{c}}$, Hideki Matsui*, ${ }^{*}$, Shiroh Futaki*,a

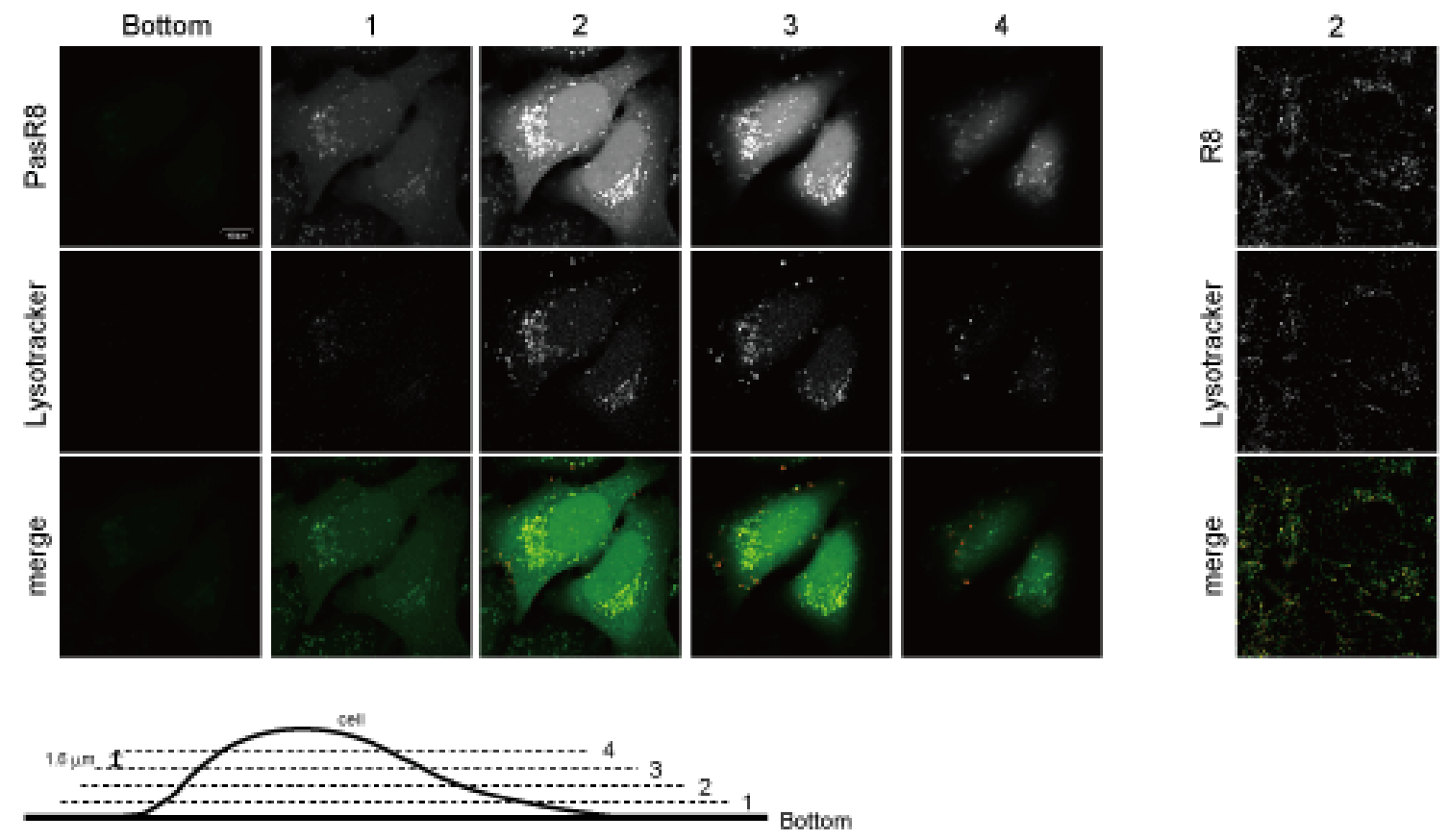

Fig. S1 z-Stack CLSM analysis of cytosolic diffusion of PasR8. HeLa cells were treated with $10 \mu \mathrm{M}$ PasR8 or R8 for $180 \mathrm{~min}$ at $37^{\circ} \mathrm{C}$ in $\alpha$-MEM(+). Cells were washed three times with PBS after incubation, treated with Lysotracker $(50 \mathrm{nM})$ (Invitrogen) for $1 \mathrm{~min}$ at $37^{\circ} \mathrm{C}$ in $\alpha-\mathrm{MEM}(+)$ and then observed by CLSM without fixation. Each picture represents a 1.6- $\mu \mathrm{m}$ interval. Scale bars, $10 \mu \mathrm{m}$. 


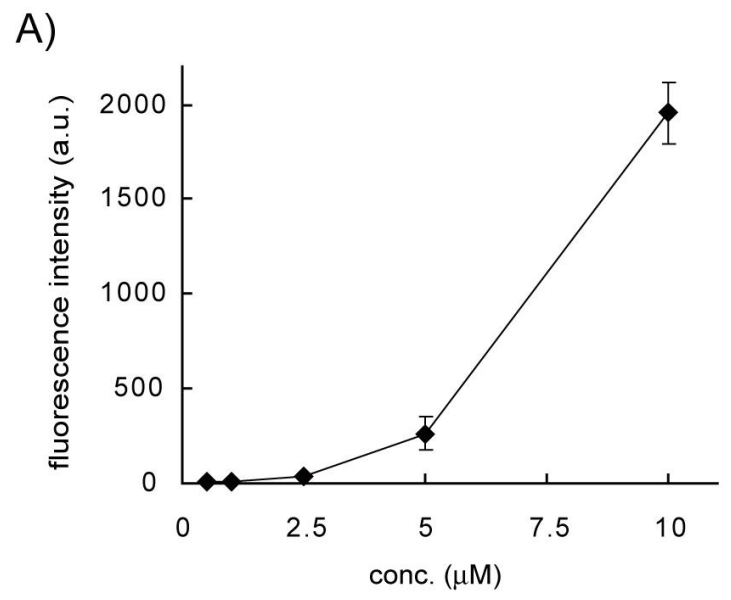

B)

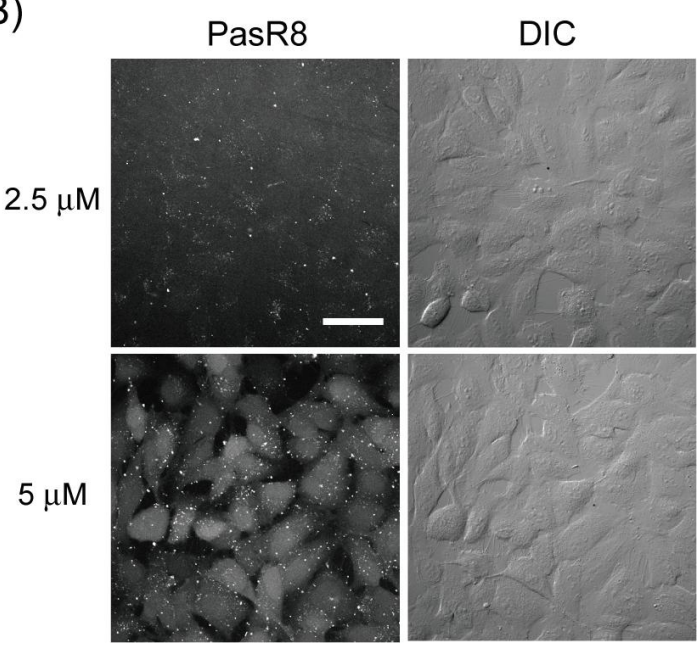

Fig. S2 Concentration-dependent cellular uptake of PasR8. A) HeLa cells were treated with PasR8 $(0.5,1,2.5,5$ and $10 \mu \mathrm{M})$ for $15 \mathrm{~min}$ at $37^{\circ} \mathrm{C}$ in $\alpha-\mathrm{MEM}(+)$ prior to analysis by flow cytometory. Experiments were performed in triplicate. Error bars show the s.d. B) HeLa cells were treated with peptides $(2.5$ and $5 \mu \mathrm{M})$ for $15 \mathrm{~min}$ at $37{ }^{\circ} \mathrm{C}$ in $\alpha-\operatorname{MEM}(+)$. Cells were then washed three times with PBS and subjected to CLSM analysis without fixation. Scale bars, $50 \mu \mathrm{m}$. 


\section{A) PasTat}

FFLIPKGGRKKRRQRRRPPQGC(Alexa)-amide

$\underline{\text { Tat }}$

GRKKRRQRRRPPQGC(Alexa)-amide

B)

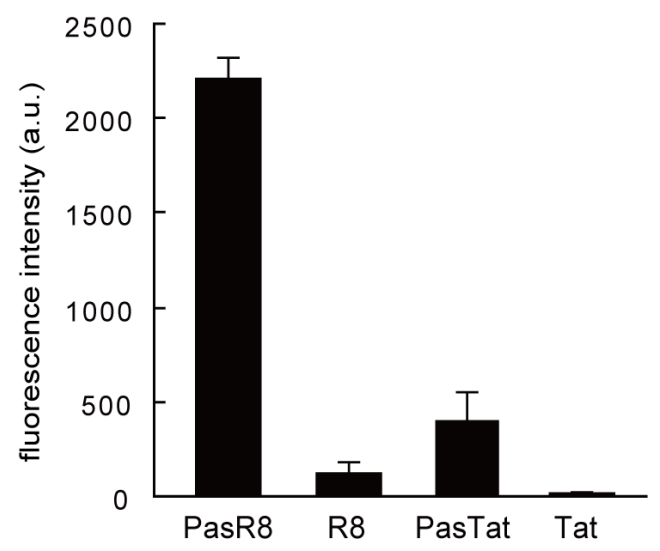

Fig. S3 Comparison of the cellular uptake efficiency of PasTat and PasR8. HeLa cells were treated with each peptide $(10 \mu \mathrm{M})$ for $15 \mathrm{~min}$ at $37^{\circ} \mathrm{C}$ in $\alpha-\operatorname{MEM}(+)$ prior to the FACS analysis. Means \pm s.d. of three experiments are shown. 
A)

PasFHV-p53C' FELIPKGRRRRNRTRRNRRRVR-G-KKHRSTSQGKKSKLHSSHARSG-amide

dPasR8-p53C

FFLIPKGRRRRRRRR-G-KKHRSTSQGKKSKLHSSHARSG-amide

dR8-p53C

RRRRRRRR-G-KKHRSTSQGKKSKLHSSHARSG-amide

B)
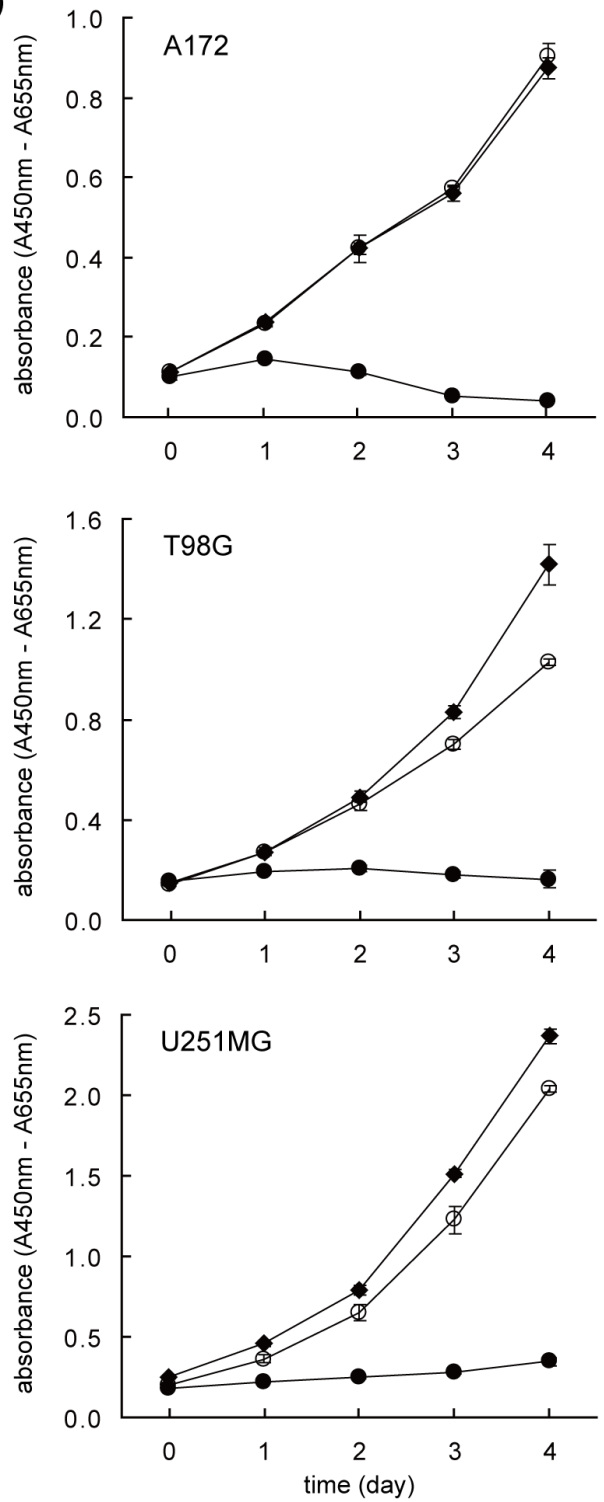

C)
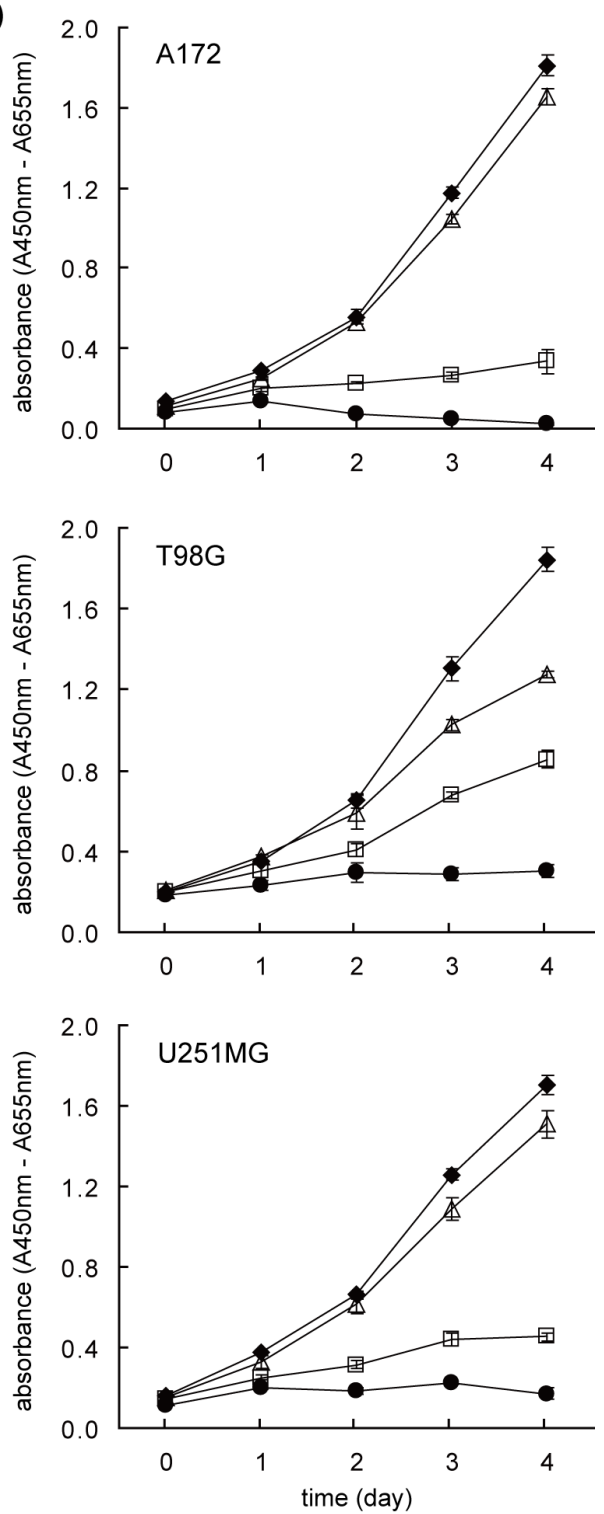

Fig. S4 A) Structures of dPasR8-p53C', dR8-p53C' and PasFHV-p53C'. The Pas segment is highlighted by the dashed line. D-amino acids are shown in italics. A Gly residue was inserted as a linker for connection between the CPP moieties and the p53 $\mathrm{C}^{\prime}$ segments. B) Employment of D-amino acid versions of the CPP is important to attain prolonged inhibition of the human malignant glioma cell growth. Closed circle, dPasFHV-p53C'; open circle, PasFHV-p53C'; closed diamond, control. Peptide, $10 \mu \mathrm{M}$. C) Superior anti-proliferation activity of dPasFHV-p53C' over dPasR8-p53C'. Closed circle, dPasFHV-p53C'; open triangle, dR8-p53C'; open square, dPasR8-p53C'; closed diamond, control. Peptide, $10 \mu \mathrm{M}$. Incubation, 4, 24, 48, 72 and $96 \mathrm{~h}$ (day 0-4) at $37{ }^{\circ} \mathrm{C}$ in $\operatorname{DMEM}(+)$. Means \pm s.d. of three experiments are shown. 